\title{
Publisher's Note: Experimental investigation of stimulated Raman and Brillouin scattering instabilities driven by two successive collinear picosecond laser pulses [Phys. Rev. E 93, 043209 (2016)]
}

\section{Rousseaux, S. D. Baton, D. Bénisti, L. Gremillet, B. Loupias, F. Philippe, V. Tassin, F. Amiranoff, J. L. Kline,}

D. S. Montgomery, and B. B. Afeyan

(Received 18 May 2016; published 24 May 2016)

DOI: 10.1103/PhysRevE.93.059905

This paper was published online on 26 April 2016 with an error in Fig. 2. Figure 2 has been replaced as of 18 May 2016. The figure is incorrect in the printed version of the journal; therefore for the benefit of the print readership, the figure and its caption are replicated below.

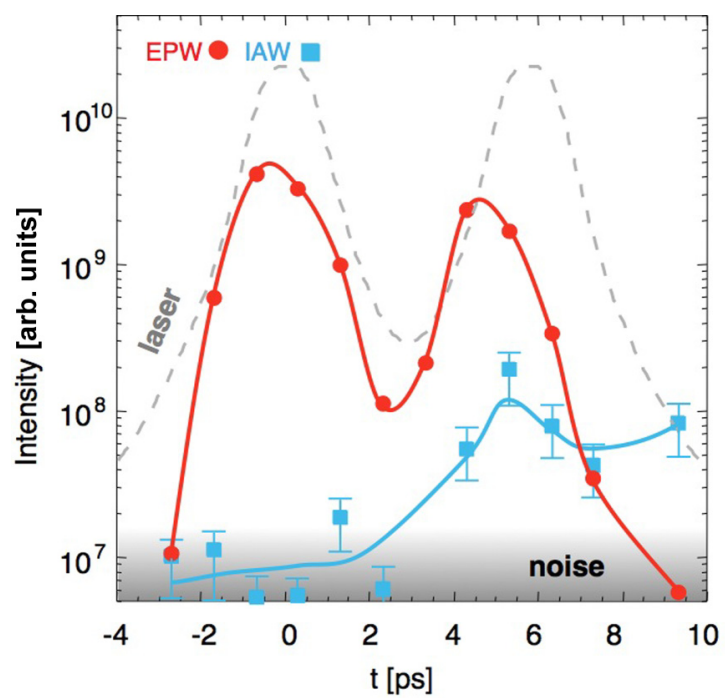

FIG. 2. Temporal evolution of the SRS-EPW (red circles) and SBS-IAW (blue squares) driven by two 1.5-ps laser pulses (dashed gray line) with a 5.8-ps time delay. $I_{0}=2 \times 10^{16} \mathrm{~W} \mathrm{~cm}^{-2}$ and $n_{e}=2.5 \times 10^{19} \mathrm{~cm}^{-3}$. Same scales as in Fig. 1 . 